\title{
Decision-making Processes for a Patient Admitted to the Accident and Emergency Department Requiring Emergency Abdominal X-ray - A Case Study
}

\author{
Y. YULIAWATI
}

\begin{abstract}
This study investigated the application of the various processes involved in decision-making for a case requiring radiologic emergency abdominal X-ray examination to the Accident and Emergency Department in a government-owned hospital in West Java, Indonesia. It is also aimed to evaluate the patient who was experiencing abdominal pain accompanied by bloating, vomiting, severe constipation and abdominal cramps.
\end{abstract}

The decision-making models used for this case were the normative, prescriptive and descriptive judgments. A decision tree in the form of decision options that was employed in this case addressed the normative model of decision-making, while the algorithm and information processing theory focused on the prescriptive model. Lastly, the intuition that was used in this case concentrated on the descriptive model of decision-making.

An emergency abdominal X-ray was indicated for the patient — a prescriptive decision. Options from decision trees were also practiced. However, the patient was in pain; therefore, she was unable to understand the alternatives that were presented. Hence, this choice was suggested by the author because, by intuition, the expectation was that the patient suffered from acute abdominal crisis.

Key words: Decision-making; case study; abdominal X-ray; A\&E Department; West Java, Indonesia

This case study aims to apply the processes of decision-making for a patient requiring radiologic emergency abdominal X-ray examination admitted to the accident and emergency (A\&E) department in a governmentowned hospital in West Java, Indonesia. It also aims to evaluate the patient who is experiencing abdominal pain that is very unusual accompanied by bloating, vomiting, severe constipation, and abdominal cramps.

The purpose of this case is to allow decision-makers to have a world view on how decisions are made with minimal errors. A sound decision can achieve this, having patients or relatives and others significant who takes part in decision-making (Thompson \& Dowding 2002).

ATRO Nusantara, Indonesia, Jalan Utan Kayu No. 67, Matraman, Jakarta Timur, Jakarta 13120, Indonesia

* Correspondence (e-mail: yeyen_yuliawati@yahoo.com) 


\section{BACKGROUND}

Decision-making in Indonesia is already done autonomously with the development of central and local government programme. There are a lot of basic radiologic examinations in major health centers that are nowadays independently decided upon by radiographers to help lessen the workload of physicians-in-charge, and that formal written referrals may not be necessary (Regulation of the Minister of Health No. 290 / Menkes / Per / III / 2008). Large hospitals may also have independent healthcare practitioners who diagnose certain diseases (Decree of the Minister of Health No. 631 / Menkes / SK / IV / 2005).

Also, autonomously deciding on plain radiographic examinations in cases of emergencies in underdeveloped countries are now at large (Regulation of the Minister of Health No. 290 / Menkes / Per / III / 2008). For example, an acute abdominal pain can be decided upon for treatment, care, diagnostic examination, and management by any healthcare professionals.

This is because an acute abdominal pain will more likely lead to chronic cholecystitis, biliary colic, hepatitis, hepatic congestion, peptic ulcer, gastroesophageal reflux disease (GERD), chronic pancreatitis, irritable bowel syndrome, diverticulitis with constipation, ovarian tumors for female, pelvic inflammatory disease (PID), Crohn's disease and mesenteric artery ischemia (McQuaid 2012). Figure 1 shows the acute abdominal diseases or disorders found in adults.

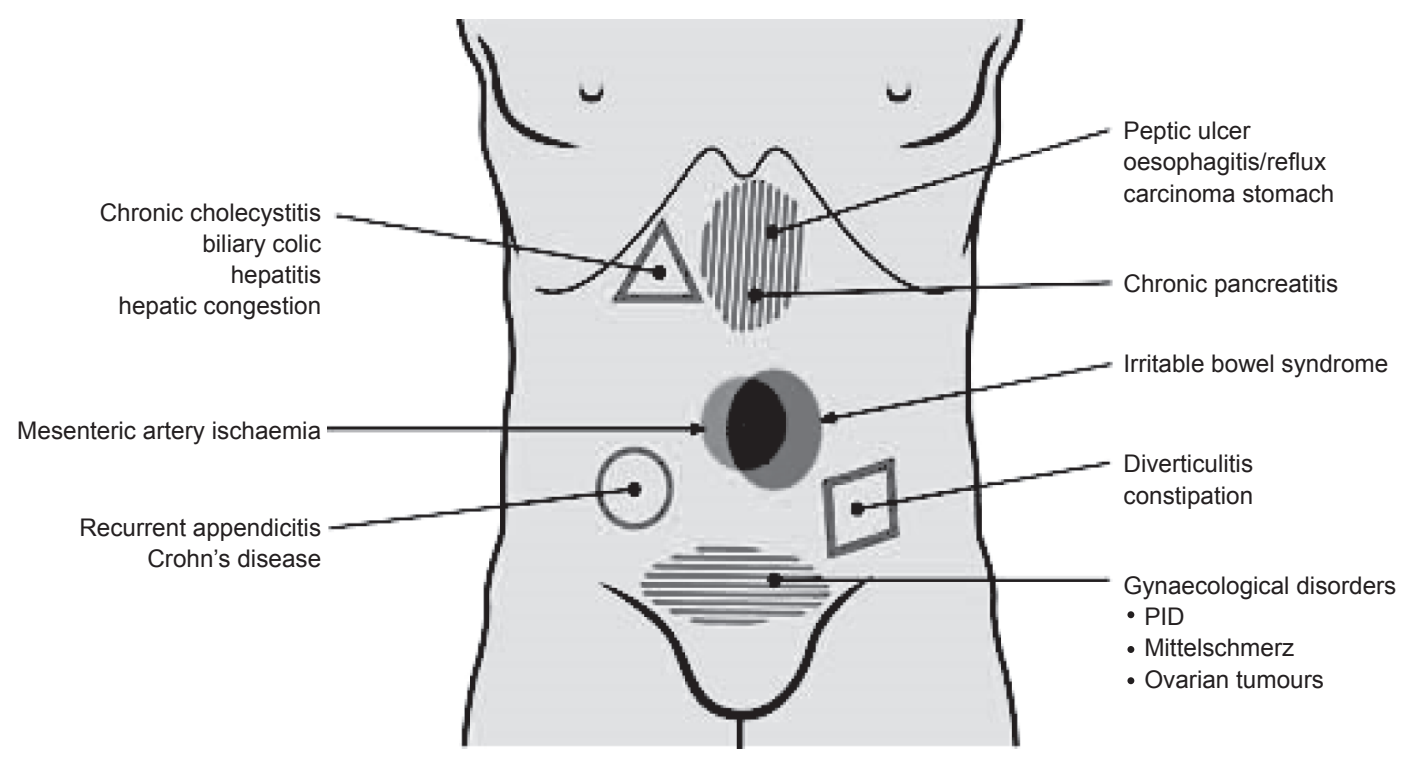

Figure 1. Acute abdominal diseases and disorders. 


\section{THE CASE}

A 60-year-old female patient with the chief complaint of abdominal pain accompanied by flatulence and abdominal cramps was admitted to the A\&E Department. An initial blood investigation was primarily done and is highlighted in Table 1.

About the patient's blood investigation result (Table 1), there was a drop in the hemoglobin which healthcare professionals should intuitively anticipate for a potential hemorrhage combined with a decreasing level of hematocrit that measures her hydration (Ministry of Health RI 2011). A drop in the patient's lymphocyte count indicates a potential inflammation of the abdomen (Ministry of Health RI 2011).

The inflammatory category of causes might be divided into two subgroups: (1) bacterial; and (2) chemical. Some typical examples

Table 1. Initial blood extraction - highlighted are the abnormal results.

\begin{tabular}{|c|c|c|}
\hline Formed elements & Result & Normal values \\
\hline - Hemoglobin & $11.0 \mathrm{~g} / \mathrm{dl}$ & $M: 13-16 F: 12-14$ \\
\hline - Hematocrit & $31 \%$ & $M: 40-48 F: 37-43$ \\
\hline - Erythrocytes & $3.7 \mathrm{million} / \mu \mathrm{l}$ & $M: 4.5-5.5 F: 4.0-5.0$ \\
\hline - Platelets & 429000 thousand $/ \mu 1$ & $150000-450000$ \\
\hline - Leukocyte & 11100 thousand $/ \mu \mathrm{l}$ & $5000-10000$ \\
\hline - $\quad$ Basophil & $0 \%$ & $0-1$ \\
\hline - Eosinophil & $2 \%$ & $1-3$ \\
\hline - $\quad$ Trunk & $2 \%$ & $2-6$ \\
\hline - Segment & $80 \%$ & $50-70$ \\
\hline - Lymphocyte & $13 \%$ & $20-40$ \\
\hline - Monocytes & $3 \%$ & $2-8$ \\
\hline Blood chemistry & Result & Normal values \\
\hline - Random glucose & $118 \mathrm{mg} / \mathrm{dl}$ & $70-140$ \\
\hline - Blood urea nitrogen & $8 \mathrm{mg} / \mathrm{dl}$ & $8-20 \mathrm{mg} / \mathrm{dl}$ \\
\hline - Creatinine & $1 \mathrm{mg} / \mathrm{dl}$ & $\begin{array}{l}1-1.2 \mathrm{mg} / \mathrm{dl} \text { with two kidneys } \\
1.8-1.9 \mathrm{mg} / \mathrm{dl} \text { with one kidney }\end{array}$ \\
\hline - Sodium & $156 \mathrm{mEq} / \mathbf{l}$ & $135-147$ \\
\hline - $\quad$ Potassium & $2.7 \mathrm{mEq} / 1$ & $3.5-5.5$ \\
\hline
\end{tabular}


of the bacterial causes will include acute appendicitis, diverticulitis, and some cases of pelvic inflammatory disease (Abdullah \& Firmansyah 2012). An abnormal result of the leukocyte, lymphocyte, and segments (Table 1), indicates an inflammation that the patient is experiencing (Abdullah \& Firmansyah 2012; Eisenberg 2008).

An example of a chemical cause would be a perforation of a peptic ulcer, where spillage of acid gastric contents causes an intense peritoneal reaction (Eisenberg 2008). While an increase in sodium decrease in potassium from the patient's blood investigation (Table 1) indicates fluid retention in the peritoneal cavity (McQuaid 2012).
After the algorithm found in Figure 2 was carried out, the next step was to explicitly decide on the type of abdominal X-ray to be done for cases of acute abdomen pain. There were three different X-rays choosen specifically for patients with severe abdominal pain.

Table 2 enumerates the prescriptive types of abdominal X-rays that have not been indicated by the physician in the A\&E Department of the said hospital, hence it was decided upon by the author (the radiographer).

The decision of the author was primarily intuitive based on recognized pattern of same signs and symptoms that were experienced by other patients with similar cases who eventually

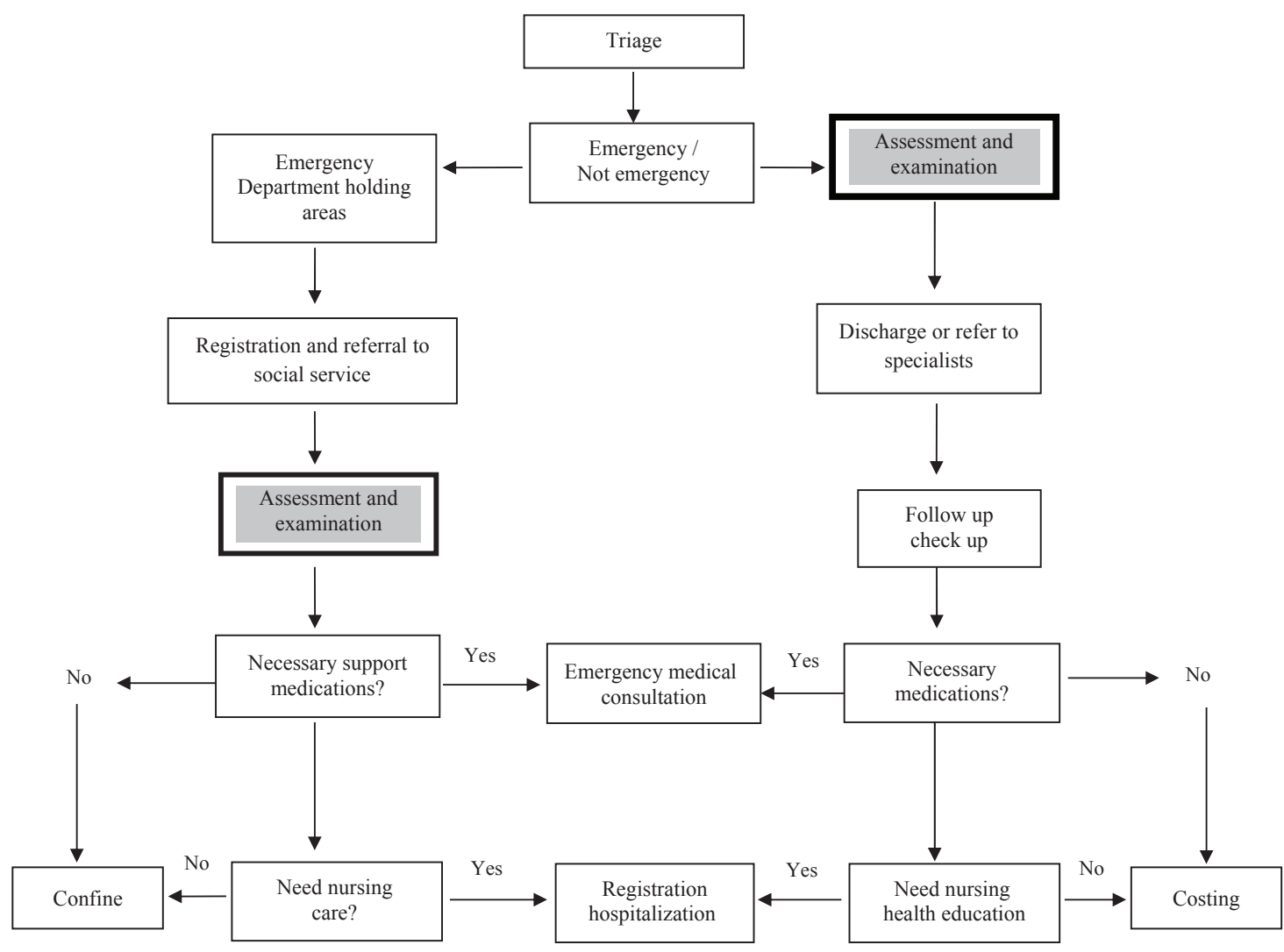

Figure 2. Algorithm for managing, treating and caring for patients in the $A \& E$ department of a government-owned hospital in West Java, Indonesia. 
Table 2. Clinical guidelines on the types of abdominal X-rays (Bontrager et al. 2012).

\begin{tabular}{l|l}
\hline \multicolumn{1}{c|}{ Type of abdominal X-ray } & \multicolumn{1}{c}{ Indication } \\
\hline \multirow{2}{*}{ Plain } & Suspected bowel obstruction/ perforation with dilated loop \\
& Suspected intussusception \\
& Suspicious abdominal mass \\
Erect & Suspected bowel obstruction to exclude perforation \\
Antero-posterior & Foreign body ingestion \\
\hline
\end{tabular}

required a plain abdominal X-ray. Besides, clinical guideline prescribes plain abdominal $\mathrm{X}$-ray that may help visualize possible suspected bowel obstruction, perforation with dilated intestinal loops, intussusception and abdominal mass (Kellow et al. 2008).

Although erect and anterior-posterior abdominal X-ray is also theoretically important to be considered done, it is also by intuition that the patient may not be experiencing foreign body ingestion and more likely having a perforation of the bowels (Balinger 2012).

The main symptom that was experienced by the patient such as prominent sudden severe pain in the abdominal area was confirmed after a physical examination and interpretation of the blood investigation.
Therefore, it was intuitively decided upon by the author that the patient's acute abdomen required a plain abdominal X-ray. Surgery could be decided after a plain abdominal X-ray result was done, to avoid potential delays that could cause complications and result in heightened mortality.

Nevertheless, options were still presented to the patient (Figure 3), showing selections whether to perform an emergency abdominal $\mathrm{X}$-ray or delay the procedure and to wait for arrival of the physicians.

The decision tree for decision options are necessary to be considered since the patient is the key decision maker (Sabiston 2004; Dioso 2015).

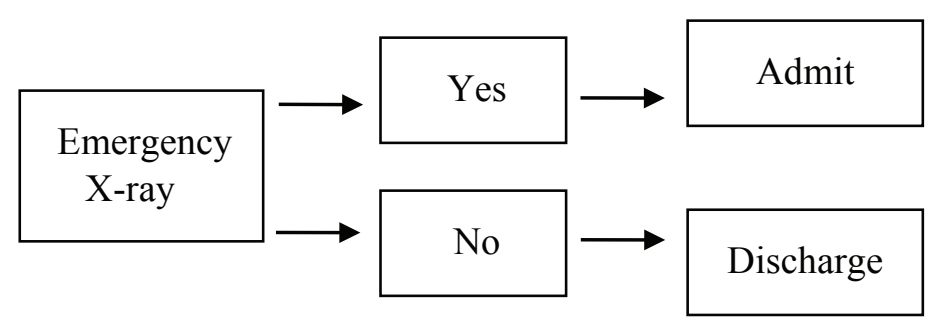

Figure 3. Decision tree as decision options presented to the patient. 
The author finally decided that an emergency abdominal X-ray was necessary. Figure 4 below shows the intra-abdominal $\mathrm{X}$-ray of the patient that was visualized in the right supine position and that can be life threatening if surgical repair was delayed.

\section{METHODOLOGY}

The decision-making models used for this case are the normative, prescriptive and descriptive judgements. A decision tree in the form of decision options that was employed in this case addresses the normative model of decisionmaking, while the algorithm addresses the prescriptive model and lastly, the intuition that was used in this case addresses the descriptive model of decision-making (Thompson \& Dowding 2002). Table 4 below summarizes the decision-making process that was used for this case.

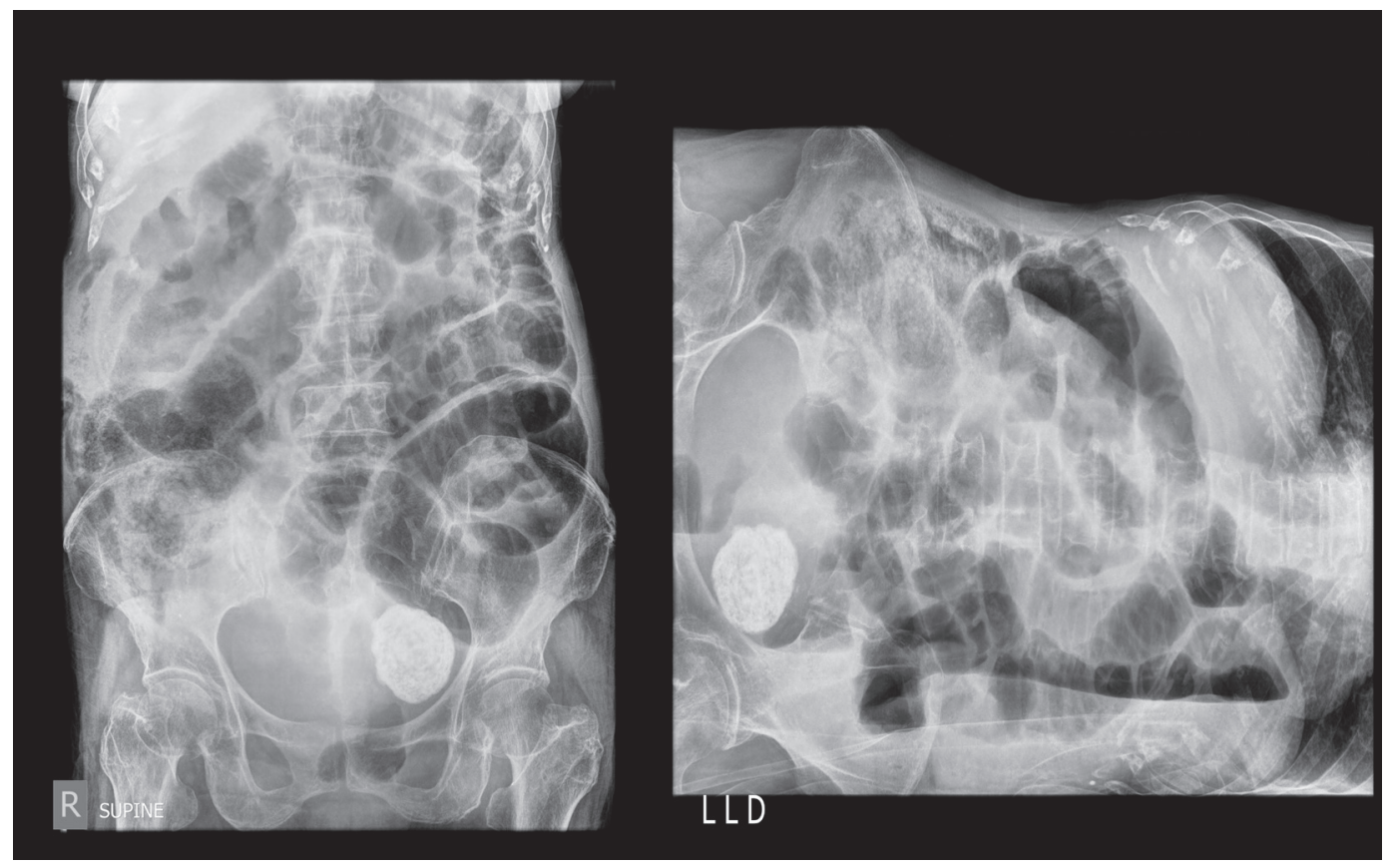

Figure 4. Abdominal X-ray result on right supine and left. 
Table 4. Summary of three decision-making models (Dioso 2015).

\begin{tabular}{|c|c|}
\hline Item & Normative model \\
\hline Characteristics & Rational, logical, scientific, evidence-based decisions. \\
\hline $\begin{array}{l}\text { Information } \\
\text { sources }\end{array}$ & $\begin{array}{l}\text { Statistical analysis of large-scale experimental and survey research which is } \\
\text { representative of a target population where the findings can be applied. }\end{array}$ \\
\hline Examples & Decision options \\
\hline Advantages & $\begin{array}{l}\text { Enable decision-makers to predict and explain the outcomes of decisions. } \\
\text { Minimize judgment errors from "base rate neglect". }\end{array}$ \\
\hline \multicolumn{2}{|r|}{ Prescriptive model } \\
\hline Characteristics & Frameworks or guidelines designed to enhance specific decision tasks. \\
\hline $\begin{array}{l}\text { Information } \\
\text { sources }\end{array}$ & $\begin{array}{l}\text { Principles and findings of previous scientific research (associated with normative } \\
\text { models). }\end{array}$ \\
\hline Examples & Information processing theory. \\
\hline Advantage & Facilitating more efficient decision-making. \\
\hline \multicolumn{2}{|r|}{ Descriptive model } \\
\hline Characteristics & $\begin{array}{l}\text { Understanding how individuals make judgments and decisions focusing on the } \\
\text { actual conditions, contexts, ecologies, and environments in which they are made. }\end{array}$ \\
\hline $\begin{array}{l}\text { Information } \\
\text { sources }\end{array}$ & $\begin{array}{l}\text { Observation, description and analysis of how decisions are made by managers } \\
\text { and professionals with their day-to-day responsibilities. }\end{array}$ \\
\hline Examples & Intuition \\
\hline Advantage & $\begin{array}{l}\text { Adequacy in supporting assumptions made about decision-making processes } \\
\text { with relevant examples from a suitable period of observation. }\end{array}$ \\
\hline
\end{tabular}




\section{Prescriptive Decision-making Model}

Information processing theory (IPT) used the algorithm and clinical guidelines.

\section{IPT Step One: Cue acquisition}

Based on the results of blood tests carried out on the patient, it showed that pain under the left side of the abdomen was acute. Healthcare professionals who took the patient's blood sample which showed that cues acquired such as the serum sodium level was increased, while venous hemoglobin, hematocrit, lymphocyte and erythrocyte and potassium decreased. More importantly, the physical examination done to assess the intensity of the abdominal pain was also used to support the blood investigation results.

\section{IPT Step Two: Hypothesis Generation}

Acute abdomen is hypothesized as a condition that occurs suddenly with the main symptoms that arise which are abdominal pain and that is life threatening. It is also hypothesized that $5 \%-10 \%$ of all emergency visits to the hospital have abdominal pain that is life threatening (Grafft \& Robinson 2001; Cordell et al. 2002).

The emergency case is any condition that the opinion of the patient, his family, or whoever assumes the responsibility of bringing the patient, is of less priority if immediate medical attention is deemed necessary to save the patients' life (Thompson \& Dowding 2002). Emergency resuscitation or diagnostic procedure is hypothesized to be done until clinical experts have made a determinat ion that the patient's life or well-being is not threatened anymore (Domball \& Margulies 1996).

\section{IPT Step Three: Interpretation of Cues}

From the results of the assessment of the patient, it was interpreted that the impression of the author on the acute abdomen required abdominal examination on three positions which was supine abdominal AP, AP half-sitting and LLD (left lateral decubitus) to assess fluid water level (Figure 4). While the results obtained, suggested expertise for radiology doctors to interpret the results.

\section{IPT Step Four: Hypothesis Evaluation}

Based on the physical examination, an emergency plain abdominal X-ray was evaluated to be required immediately. The result of the emergency abdominal X-ray on Figure 4 is shown to have an obstructive ileus with suspected ovarian tumor on the right which was why an emergency plain abdominal X-ray was required.

In patients with acute abdominal examination with plain abdominal radiology, supine and standing positions, as well as thorax images, were used. But if the patient was unable to stand, the testing should use the left lateral decubitus.

Evaluation of the images should remain based on or confirmed by history, physical examination and laboratory obtained previously. A picture of the free air and dilated bowel possibility of intestinal obstruction found in Figure 4 showed a perforation. The image classification of the biliary system, kidneys and urethra was also a possibility found on the X-ray result of the patient.

It was also hypothesized that free air in the peritoneal cavity showed a perforation of the gastrointestinal tract (Figure 4). Lastly, a hydropneumoperitonium extensively appears as a picture of water fluid level that was hypothesized on the X-ray result found in Figure 4. 


\section{Normative Decision-making Model}

Decision options were presented to the ultrasonography. Ultrasound examination is useful in patients with acute abdominal pain because it could provide an evaluation that was fast, safe and cheap. As suggested by the author there was a need to do a CT scan of the abdomen soon to evaluate complaints that did not have clear indications. CT-scan was very useful in identifying intraperitoneal free air of very little time, and location inflammation areas required immediate surgery.

\section{Descriptive Decision-making Model}

By intuition, the author intuitively believed that the patient should undergo do the abdominal examination on three positions - anteriorposterior, left a lateral, and right side. Based on the results, expert specialist in radiology to the patient should obtain the following: normal peritoneal fat line; air distribution within the intestine that was not filling the pelvic cavity, did not seem to depict free intraperitoneal air, widening intestines with water fluid level; visible mass hiperdens in the left pelvic cavity; and the bones and soft tissue being normal.

It was important to trust an intuition if it was also based on recognized patterns of previously encountered similar cases. The author being an expert radiographer could intuitively perceive signs of the acute abdomen from the resulting expertise. Therefore trusting the intuition was just the same as looking back at the patterns of previously encountered cases.

However, it is important to be contious using intuition (Figure 5; Dioso 2015) during the early part of the consultation. This is because intuition is a substandard way of decisionmaking that is only characterized by a shallow understanding of actual events and conditions taking place.

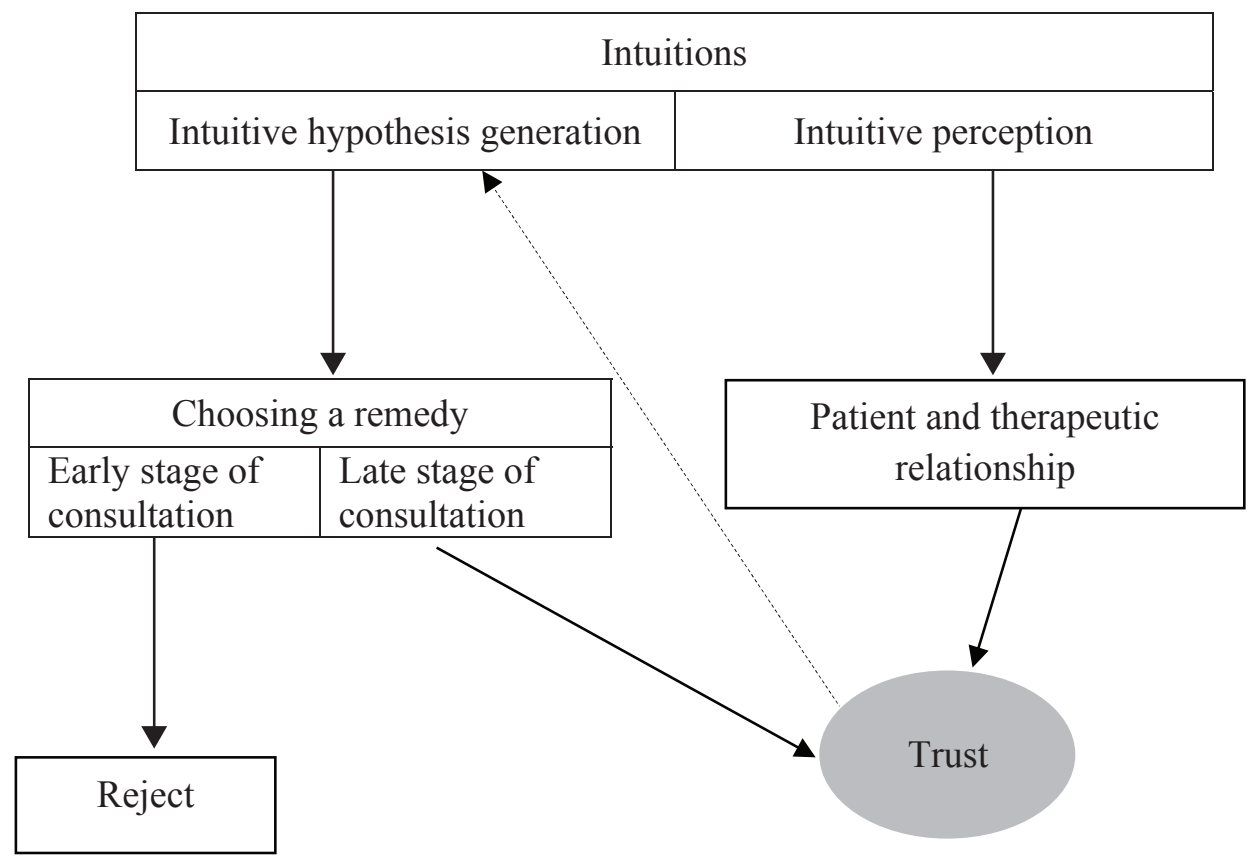

Figure 5. How to trust an intuition (Dioso 2015). 


\section{DISCUSSION}

The prescriptive decision-making made an impact in this case. The system of independently deciding for emergency abdominal X-ray is practiced already in Indonesia since this decision is more likely to be autonomously done by the radiographers. The Ministry of Health has issued a policy regarding the Standard Emergency Room (ER) Hospital contained in KEPMENKES No. 856 / Menkes / SK / IX / 2009 to regulate the standardization of emergency services at the hospital. To improve the quality of emergency in Indonesia, there needs to be a commitment to help provide socialization to the public in handling emergencies that is often not drawn to more mistakes.

Patients who go to the Emergency Department of a hospital would need help quickly and accurately for standard needs in providing emergency services in accordance with the competition of each hospital to guarantee an emergency care with a response time that is fast and precise in handling, connoting excellent hospital service (KMK 856 on the standardization of the Emergency Department).

Reviewing the case raised by the authors, the decisions that should be done was to provide education to the patient or the patient's family that was normatively done by the radiology services in providing precise information about the flow of patient care. In this case, any measures should include a letter for radiological $\mathrm{X}$-ray request of either the sender doctor for emergency cases or not, only then it would be possible for radiological examinations. Due to the Minister of Health Decree No. 375 of 2007 which is about the professional standard radiography which are related to the code of conduct for radiographers who in this case had an obligation to his profession as "radiographer just doing a job of radiography, imaging and radiotherapy at the request of doctors by not leaving the procedures outlined". This means that the radiographers in Indonesia have full autonomy to decide on the best diagnostic examination that is recommended to the patient in an emergency situation.

According to Eisenberg (2008), in a small group in the USA 25 years ago, the role of examinations for plain radiographers can reduce the risk of further complications up to $50 \%$ without loss of clinical findings.

Risks of abdominal pain of moderate to severe, and the obvious clinical symptoms may lead to intestinal obstruction, ureter stones, ischemia, or diseases of the gallbladder (Kellow et al. 2008). In a retrospective study it was found that $40 \%$ of photo plain radiographs of the abdomen was considered normal had to be followed up with additional advanced checks which discovered the abnormal condition of $72 \%$ so the current role of photo plain radiographs of the abdomen benefitted that which was taken over by CT scan and ultrasound.

Field (1998) stated that the examination of plain radiographs remains as the very useful and valuable inspection of the initial investigation and make the clinician decide whether patients with acute abdomen pain requires surgery or not; and if necessary, whether immediate surgery or whether it still can be delayed so that other tests can be done to support the diagnosis.

\section{RECOMMENDATIONS}

It was recommended that patients in private hospitals in Indonesia who were not capable of paying their hospital bills should limit the usage of technology such as X-ray machine. Intuitions were recommended especially if the main complaint was recognized to be similar to previously encountered cases. In this way, the impact of decisions gave more benefits than harm to the patient. 
It was still however recommended that in a fast paced environment, the use of clinical guidelines should be considered as the safest decision-making process. Explaining to the patient the advantages of each diagnostic examination for the patient to understand clearly the options provided was the better decisionmaking process.

\section{CONCLUSION}

It was therefore concluded that in this case, the decision-making process used the prescriptive model substantiated by intuition. The X-ray examination carried out by plain abdominal anterior-posterior, and lateral view found abnormalities in the abdominal cavity. Options on decision trees were also practiced; however the patient was in pain. Therefore, she was unable to understand the choices that were presented. Hence, the alternatives were suggested by the author. Fast and accurate action was needed for these patients, given the emergency situation. Therefore, decision-makers must always be in psychological and intellectual control to demonstrate sound decision.

\section{ACKNOWLEDGEMENT}

Lecturer Regidor III is appreciated for the supervision of this study.

Date of receipt: January 2016 Date of acceptance: March 2016

\section{REFERENCES}

Bontrager, KL and Laphignano, J 2012, Text book of radiographic positioning and related anatomy. 6th edn, Elsevie, Mosby.

Decree of the Minister of Health No. 631/ Menkes / SK / IV / 2005, Guidelines for Medical Staff Internal Rules (Medical Staff Bylaws) in Hospital Clinical Data Interpretation Guidelines 2011, Ministry of Health.
Dioso, R III 2015, 'Decision-making processes for a do-not-resuscitate poisoned pediatric patient admitted to the department of emergency and medical services', ASEAN Journal of Science and Technology for Development, vol. 15, no. 2, pp. 15-21.

Eisenberg, LR 2008, 'The role of abdominal radiography in the evaluation of the nontrauma emergency patient: new thought on an old problem', Radiology, vol. 248, pp. 715-716.

Field 1997, Plain abdomen in diagnostic and interventional radiology in surgical practice, $\mathrm{P}$ amstrong \& ML Wasti, eds, London, Chapman and Hall Medical.

Heading, RC 1999, 'Prevalence of upper gastrointestinal symptom in general population : a systemic review', Scand J. Gastroenterrol., (Suppl.) pp. 231.3

Kellow, SZ, Maclinnes, M, Kurzencwyg, D, Rawal, S, Jaffer, R et al. 2008, 'The role of abdominal radiography in the evaluation of the non-trauma emergency patients', Radiology, vol. 248, pp. 887-893.

Ministry of Health, KMK No. 375/ 2007, About professional standards Radiographer Regulation of the Minister of Health No. 290 / Menkes / Per / III / 2008 on Approval of Actions of Medicine.

McQuaid, K 2012, Approach to the patient with gastrointestinal disease, L Goldman ed, Goldman's Cecil Medicine, 24 edn, Philadelphia, Elveiser.

Murdani, A \& Firmansyah, MA 2012, Diagnostic approach and management of acute abdominal, Departement of Internal Medicine, Faculty of Medicine, University of Indonesia - Cipto Mangun Kusumo Hospital, Central Jakarta, Indonesia. 